Amsel, A., Rashotte, M. E., \& MacKinnon, J. R. Partial reinforcement effects within subjects and between subjects. Psychological Monographs, 1966, 80(20 Whole No. 628).

Brown, R. T., \& Logan, F. A. Generalized partial reinforcement effect. Journal of Comparative \& Physiological Psychology, $1965,60,64-69$.

Rashotte, M. E., \& Amsel, A. The generalized PRE: Within-S PRF and CRF training in different runways, at different times of day, by different experimenters. Psychonomic Science, $1968,11,315-316$.
Mowrer, O. H. Learning theory and behavior. New York: Wiley, 1960.

Young, A. G. Resistance to extinction as a function of partial reinforcement and bar weighting: A within-Ss design. Journal of Experimental Psychology, 1969, 79, 363-367.

(Received for publication March 14, 1974.)

\title{
Backward masking of gratings varying in spatial frequency*
}

\author{
WILLIAM N. DEMBER, MARY STEFL, and KATHY C. KAO \\ University of Cincinnati, Cincinnati, Ohio 45221
}

\begin{abstract}
Previous research tested the susceptibility to backward masking of disk-shaped targets with varying numbers of internal pie-shaped segments. In general, the greater the number of segments, the harder was the target to detect (spatial forced-choice task) and also the harder to mask. Furthermore, certain targets were unmaskable and the detectability of others was enhanced by the masking stimulus (a black ring). The present experiment tested the generality of those findings using, as targets, disks with internal segments comprising gratings varying in spatial frequency; the earlier results were generally replicated, except that there was little evidence of backward enhancement.
\end{abstract}

In previous research, we uncovered a target variable with considerable impact on visual backward masking. The variable was suggested by Werner's (1935) observation that targets with internal contours are less susceptible to masking than are homogeneous targets, presumably because the former have greater figural strength. Our initial experiment (Sherrick \& Dember,

\footnotetext{
* Supported by Grant GB 33621 from the National Science Foundation to William N. Dember. Reprints should be requested from William N. Dember, Department of Psychology, University of Cincinnati, Cincinnati, Ohio 45221.
}

1970) employed disk-shaped targets which were black on one side of the diameter and white on the other; we thought of them as having one internal contour. Such targets did prove harder to mask (by a black ring) than homogeneous black disks.

To determine whether there was a quantitative relation between susceptibility to masking and number of internal contours, we again employed disk-shaped targets that were half black and half white. Number of internal contours was manipulated by varying the number of pie-shaped alternating black and white 
segments which the target disk comprised. To check on possible effects this manipulation might have on target detectability per se, we included a control condition in which each target's detectability was measured (duration threshold) in the absence of the masking figure.

A series of experiments (Cox \& Dember, 1970; Dember, Mathews, \& Stefl, 1973; Dember \& Stefl, 1972; Ellis \& Dember, 1971) revealed that: (1) the greater the number of segments, the harder the target is to detect in the nonmasking condition; (2) relative to its nonmasked detectability, the greater the number of segments, the easier the target is to detect in the masking condition; (3) certain targets are virtually unmaskable and others are even easier to detect in the masking than in the nonmasking condition.

The first finding was unexpected, but not especially puzzling: increasing the number of segments might be tantamount to transforming the target into one that increasingly approaches the limit of visual acuity and hence functions like a homogeneous gray disk. The second finding is, of course, the one predicted from Werner's observation. The discovery that the detectability of certain targets is either unaffected by or even enhanced by the masking figure was both unexpected ${ }^{1}$ and intriguing. Those results do not fit any model of masking, for the obvious reason that all such models have been developed to account for the opposite effect-i.e., target inhibition under masking conditions (see, for example, Bridgeman, 1971; Turvey, 1973; Weisstein, 1968).

The purpose of the present study was to explore the generality of our previous findings by employing target disks with varying numbers of parallel, black and white segments (i.e., gratings varying in spatial frequency). The special nature of gratings has recently been emphasized (e.g., Cornsweet, 1970; Davidson, 1968; Maffei, Fiorentini, \& Bisti, 1973; McCulloch, 1965); their possible relevance to backward masking has not yet been reported.

\section{METHOD}

\section{Subjects}

Eight college students (five men, three women) with normal or corrected-to-normal vision served as paid Ss. All Ss received training on the psychophysical task, as described below, but were otherwise naive about the purpose of the experiment.

\section{Stimuli}

Six target stimuli were used, a homogeneous black disk and disks containing $4,6,8,16$, or 32 alternating black and white stripes. Disk diameter was $8 \mathrm{~mm}$ (22.6 min of arc). The target stimuli were presented on a background of gray paper, which reflected $50 \%$ of the incident light. The masking stimulus consisted of a pair of black rings mounted on the same gray paper. The inner diameter of each ring was $8 \mathrm{~mm}$, and the outer diameter was $16 \mathrm{~mm}(45.2 \mathrm{~min}$ of arc). The two rings were arrayed along the horizontal axis with their centers $18 \mathrm{~mm}$ apart (51.7 min of arc). The dual ring masking stimulus was used to accommodate the spatial forced-choice psychophysical procedure described below.
Each of the grating targets was used in both a vertical and horizontal orientation; the black disk was treated in the experimental design as though it could have both orientations.

\section{Design}

A totally repeated measures design was used, with factorial combination of six target types, two target orien tations, and two masking conditions (masking rings present or absent). A separate random order of the resulting 24 combinations was used for each S.

\section{Apparatus and Procedure}

The stimuli were presented in a three-channel Scientific Prototype tachistoscope (Model GB). Viewing was monocular. The target stimulus was fixed to a movable plate which allowed the $\mathrm{E}$ to center the disk precisely in the location of one of the two masking rings (or where a ring would have been in the case of the nonmasking condition). Target location was random from trial to trial.

A trial consisted of the following sequence: fixation field target field - mask field - fixation field. All fields were illuminated at $10 \mathrm{fL}$. The fixation field contained four red dots in a diamond pattern which circumscribed the locus of the to-be-presented target and mask displays. There was no interval between the termination of the target field and the onset of the mask field. Mask-field duration was $100 \mathrm{msec}$. Target-field duration was variable, as required by the psychophysical procedure.

A trial was initiated by the S's depressing a button on signal from the E. Immediately at the end of the trial, the $S$ indicated target location by saying "left" or "right," guessing when necessary.

Duration thresholds were obtained according to the double staircase variant of the method of limits (Dixon \& Massey, 1969). One staircase constituted an ascending series and the other a descending series. The two staircases were intermixed to minimize errors of anticipation. Which staircase a given trial belonged to was determined randomly, with the constraint that every block of 10 trials contain 5 trials from each staircase.

The following rules were used to determine target duration: If the $\mathrm{S}$ was correct on two successive trials belonging to a given staircase, the $\mathrm{E}$ decreased target duration for the next trial on that staircase; if the $S$ was incorrect on one trial, target duration was increased for the next trial on that staircase.

Ten trials were run at the beginning of each threshold determination to help estimate the range of target duration values in which the threshold was likely to fall. For those $\mathbf{1 0}$ preliminary trials, the size of the target duration increment or decrement was $2 \mathrm{msec}$. For the subsequent 70 test trials, the increment or decrement was $0.5 \mathrm{msec}$. In the computation of the threshold, only the results of the final 60 test trials were used.

Prior to the start of the experiment proper, each $\mathrm{S}$ was given a $1 \frac{11 / 2-h}{}$ training session on each of 2 successive days. A total of 20 trials was run on each of the 24 combinations of target type, target orientation, and masking condition. For half of these training trials, target duration was set at $10 \mathrm{msec}$, and for half at $25 \mathrm{msec}$.

Following the 2 training days, a duration threshold was obtained for each of the 24 combinations, two threshold determinations per day in a total session lasting about $1 \frac{1 / 2}{h}$. Before the start of each day's session, the $S$ was dark-adapted for $5 \mathrm{~min}$; a 10-min break was given between the two daily threshold determinations.

\section{RESULTS AND DISCUSSION}

The duration thresholds were subjected to an analysis of variance. Data from the homogeneous black target 
Table 1

Mean Duration Thresholds (Milliseconds) Averaged Over Target Orientation

\begin{tabular}{lcccccr}
\hline & \multicolumn{5}{c}{ Target Type (Number of Segments) } \\
\cline { 2 - 7 } Condition & 0 & 4 & 6 & 8 & 16 & 32 \\
\hline No Mask & 3.21 & 2.47 & 3.30 & 4.83 & 8.80 & 8.59 \\
Mask & 20.34 & 3.82 & 3.19 & 3.24 & 13.43 & 28.94 \\
\hline
\end{tabular}

were omitted from the analysis, since they would have grossly inflated the apparent effects. The analysis showed both the target type $(F=26.41, \mathrm{df}=4, \mathrm{p}<.01)$ and the masking condition $(\mathrm{F}=13.87, \mathrm{df}=1, \mathrm{p}<.025)$ main effects to be significant; target orientation $(F=$ $1.91, \mathrm{df}=1$ ) was not. In addition, the Target Type by Masking Condition interaction was significant $(\mathrm{F}=$ $18.28, \mathrm{df}=7, \mathrm{p}<.01)$, as was the triple interaction among target type, masking condition, and target orientation $(\mathrm{F}=4.84, \mathrm{df}=1, \mathrm{p}<.05)$.

The mean duration thresholds (including the black target) are given in Table 1, averaged over orientation and Ss. The general trends are consistent with those found in our previous experiments, which used pie-shaped target segments. In particular, the Target Type by Masking Condition interaction replicates our earlier finding that as number of segments increases, the targets become both harder to detect and also relatively harder to mask. In the present data, however, that relation breaks down somewhere between the values of 8 and 16 stripes; in the Dember and Stefl (1972) experiment, which used pie-shaped segments, the break occurred between 16 and 32 segments, and in the Dember, Mathews, and Stefl (1972) experiment, the relation continued to hold for targets having as many as 32 pie-shaped segments.

The major discrepancy between the present and the earlier results lies in the paucity of evidence in this experiment of target enhancement. In only one case (eight stripes, horizontal orientation) was there a significant enhancement effect $(t=2.45$, df $=7$, $\mathrm{p}<.05)$. With the data from both orientations combined, the eight-striped target showed only marginally significant enhancement $(\mathrm{t}=1.44, \mathrm{df}=7$, $\mathrm{p}<.10)$. The six-striped target showed neither enhancement nor masking. All other targets were significantly masked $(\mathrm{p}<.05$ or smaller).

Looked at most generally, the present data seem consistent with earlier results, but the effects of greatest interest are attenuated. Before speculating seriously on possible reasons for the attenuation, we would need to replicate the present findings and, moreover, would want data collected within a single design on gratings, pie shapes, and perhaps other types of target segments. In the meantime, taking the available data at face value, we would point to the possible importance of one obvious way in which the gratings and pie-shaped segments differ: the former are distributed as parallel contours, whereas the latter intersect in the center of the target. It is conceivable that an intersecting pattern of contours is optimal for eliciting inhibitory effects from the target stimulus. If so, our earlier suggestion (Dember \& Stefl, 1972) may still be apt-i.e., that the effect of a masking stimulus on such targets is primarily disinhibitory. Thus, by analogy with the disinhibition found in experiments employing two successive masks (Dember \& Purcell, 1967; Robinson, 1966), the masking stimulus in experiments of the present sort may serve to suppress target-generated inhibition ${ }^{2}$ and hence disinhibit the excitatory effects of the target stimulus which are presumed to underlie target detection.

\section{REFERENCES}

Bridgeman, B. Metacontrast and lateral inhibition. Psychological Review, 1971, 78, 529-539.

Cornsweet, T. N. Visual perception. New York: Academic Press, 1970.

Cox, S. I., \& Dember, W. N. Backward masking of visual targets with internal contours. Psychonomic Science, 1970, 19, 255-256.

Davidson, M. L. Perturbation approach to spatial brightness interaction in human vision. Journal of the Optical Society of America, 1968, 58, 1300-1308.

Dember, W. N., \& Purcell, D. G. Recovery of masked visual targets by inhibition of the masking stimulus. Science, 1967, 157, 1335-1336.

Dember, W. N., Mathews, W. D., \& Stef1, M. Backward masking and enhancement of multisegmented visual targets. Bulletin of the Psychonomic Society, 1973, 1, 45-47.

Dember, W. N., \& Stefl, M. Backward enhancement? Science, $1972,175,93-95$.

Dixon, J. W., \& Massey, F. J. Introduction to statistical analy sis. New York: McGraw-Hill, 1969.

Donchin, E., \& Lindsley, D. B. Retroactive brightness enhancement with brief paired flashes of light. Vision Research, 1965, 5, 59-70.

Ellis, D., \& Dember, W. N. Backward masking of visual targets with internal contours: A replication. Psychonomic Science, 1971, 22, 91-92.

Kristofferson, A. B. Foveal intensity discrimination as a function of area and shape. Doctoral dissertation, University of Michigan, 1954.

Maffei, L., Fiorentini, A., \& Bisti, S. Neural correlate of perceptual adaptation to gratings. Science, 1972, 182, 1036-1038.

McCulloch, C. Color adaptation of edge-detectors in the human visual sy stem. Science, 1965, 149, 1115-1116.

Robinson, D. N. Disinhibition of visually masked stimuli. Science, 1966, 154, 157-158.

Sherrick, M. F., \& Dember, W. N. Visual backward masking and the area-detection relation. Psychonomic Science, 1970, 19, 127-128.

Turvey, M. T. On peripheral and central processes in vision: Inferences from an in formation-processing analy sis of masking with patterned stimuli. Psychological Review, 1973, 80, 1-52.

Weisstein, N. A Rashevsky-Landahl neural net: Simulation of metacontrast. Psychological Review, 1968, 75, 494-521.

Werner, H. Studies on contour: Qualitative analy ses. American Journal of Psychology, 1935, 47, 40-64.

\section{NOTES}

1. Donchin \& Lindsley (1965), using quite different stimuli and procedures, report enhanced target brightness under masking conditions.

2. The concept of target-generated inhibition was invoked by Kristofferson (1954) to account for the failure of target stimuli with intersecting contours, such as crosses, to be as detectable as his otherwise highly successful model predicted they should be.

(Received for publication March 25, 1974.) 